\title{
A CLINICAL TRIAL OF ISOCARBOXAZID ('MARPLAN') IN ANGINA PECTORIS
}

\author{
BY \\ J. M. BARBER, FRANCES M. MURPHY, AND E. A. CHEESEMAN
}

From Ards Hospital and the Queen's University of Belfast

Received August 31, 1961

The effects of long acting drugs for the prevention of angina are difficult to evaluate because they can seldom be assessed objectively. Emotional factors contributing to the frequency of attacks are also liable to influence opinions about the efficacy of new drugs. Following the investigation of monamine oxidase inhibitors for the treatment of angina pectoris, we carried out a preliminary study of tersavid (Murphy and Barber, 1960). Of our treated patients, 66 per cent claimed improvement; but in a subsequent controlled trial (Murphy et al., 1961) the drug was judged to be no more effective than a placebo.

The purpose of this trial was to assess the value of 1-benzyl-2-(5-methyl-3-isoxazolylcarbonyl) hydrazine-isocarboxazid ("marplan"), another monamine oxidase inhibitor, as an analgesic for moderate to severe angina. A group of patients were treated with marplan and a placebo, lactose, under so-called "double blind" conditions.

\section{Plan OF TRial}

In a preliminary study of this drug about 70 per cent of treated patients were thought to have been improved (Murphy and Barber, 1960). Previous experience of clinical trials, involving patients with angina pectoris, suggested that at least 35 per cent of patients given a placebo would claim considerable improvement. It was decided that if the proportion making this claim for marplan was 70 per cent or more, then the difference $(35 \%)$ between the two treatments (marplan and placebo) would be sufficiently large to be of therapeutic importance. Consequently a "within patients" trial (i.e. all patients would have both treatments) was planned with 95 per cent power of detecting such a difference at the 5 per cent level of significance, i.e. in the usual notation (Armitage, 1960): $2 \alpha=0.05,(1-\beta)=0.95, \pi_{1}=70 \%$ and $\pi_{2}=35 \%$. In this type of experiment a pair of results is obtained for each patient and it is the "untied pairs" (i.e. results of patients who report success with only one treatment) that are informative, because on the null hypothesis an equal number of preferences are expected for each treatment. On the above criteria about 30 untied pairs of results are likely to be required for a non-sequential trial and to obtain these it was estimated that the results on about 50 patients would be required.

Patients accepted for the trial were allotted to one of eight groups defined by the multiple classification of sex, age (under 55 and 55 years and over) and severity of anginal pain (moderate or severe) (see footnote to Table I). Within each group, half the patients were treated first with marplan and then with placebo and half were treated first with placebo and then with marplan. The patients were not aware that the tablets were different. The pharmacist was provided with a plan giving a series of random sequences (e.g. XY, YX, YX, XY, YX . . .) for each of the eight groups. She decided, and throughout the trial she alone knew, which letter (i.e. $X$ or $Y$ ) referred to marplan and 
which to placebo. She allotted to each patient accepted for the trial a sequence in accordance with this plan, and issued the appropriate tablets in two boxes labelled only with the order in which they were to be used.

Patients were asked to take one tablet thrice daily for six weeks (i.e. three weeks for each treatment). This dosage of marplan was equivalent to $30 \mathrm{mgm}$. per day. Nitroglycerine tablets were not discontinued during the trial. The two three-week periods ran consecutively and each patient was seen weekly by the physicians, one of whom assessed the success or failure of each treatment at the end of each three-week period from opinions given by each patient. Thus patients were not asked to state which treatment period they preferred, but were asked to give separate judgment on each period. Thus the untied pairs of results were, in this sense, "implied" preferences.

\section{RESULTS}

Of 61 patients accepted for the trial, 6 withdrew. Of these, 4 failed to attend all out-patient sessions, one was admitted as an in-patient and one forgot to take her tablets. In order to preserve in each group an equal number of patients on each treatment sequence, the last patient accepted in a group was omitted, where necessary, from the analysis. This resulted in a further 5 omissions so that the analysis is based on 50 patients and should satisfy the criteria of the design.

Table I shows the results obtained in each group and sub-divides patients according to the sequence of treatment. In all, 25 patients reported success with one treatment but not with the other. On the null hypothesis half of these patients $(12 \cdot 5)$ would be expected to have had success with each treatment; in fact 14 implied preference for marplan and 11 for the placebo. Differences between observation and expectation such as these could easily have arisen by chance $(P=0.69)$. Thus these data do not suggest any material difference in the efficacy of marplan and a placebo in the treatment of moderate or severe anginal pain when administered in the dosage used in this trial.

It is of some interest to note that the treatment given second was judged the better by more than half the patients implying a preference. Thus of the 25 patients who had marplan after the placebo, $11 \mathrm{implied}$ preferences and of these as many as 9 were in favour of marplan. This difference from the 5.5 in favour of each expected on the null hypothesis is almost significant (at the conventional 5 per cent level) as $\mathbf{P}=0 \cdot 07$. Of the 25 patients who had the placebo after marplan, 14 implied preferences and of these 9 were in favour of the placebo. Even though these numbers are not significantly different from the 7 in favour of each expected on the null hypothesis $(P=0.42)$, the consistency of these results stresses the importance of taking the sequence of treatment into account.

Examination of the results of each of the eight groups of patients reveals no exceptions to the general observations, made on all groups combined, which could not easily be explained by chance, but we must emphasize that the numbers in some groups were negligible and that the trial was not designed to make assessments for specific groups of patients. Group B (males aged 55 and over with moderate angina) is the most inconsistent. In this group there were 11 implied preferences, as many as $7(64 \%)$ being in favour of the placebo, whereas in all groups combined there were 25 preferences and only $11(44 \%)$ were in favour of the placebo. However, the observation of 7 out of 11 in favour of one treatment could easily have occurred by chance $(\mathrm{P}=0 \cdot 55)$.

\section{SIDE EFFECTS}

Side effects were minimal and occurred in six patients. One complained of dizziness on both tablets. Side effects in the other five patients occurred with the placebo and included headaches, blurring of vision, heartburn, sudden jerking movements of limbs, flushing of face, and feeling "dopey." Symptoms were not severe and did not influence assessment of the drug. Of these six patients, two improved on the drug, two on the placebo, one improved on both and the other had no improvement on either. No material variation in blood pressure was observed. 
TABLE I

RESULTS OF TRIAL

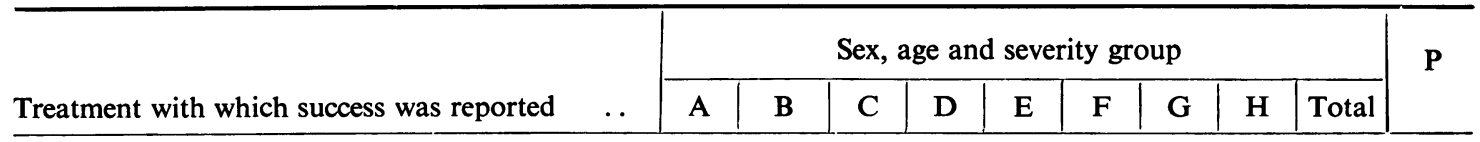

Patients who had placebo before marplan

\begin{tabular}{lllllll|l|l|l|l|l|l|l|l|l|l}
\hline Buth .. &.. &. &. &.. &. &.. & 0 & 3 & 0 & 0 & 1 & 0 & 1 & 0 & 5 & \\
$\begin{array}{l}\text { Placebo only } \\
\text { Marplan only }\end{array}$ &.. &. &.. &. &.. & 1 & 1 & 0 & 0 & 0 & 0 & 0 & 0 & 2 & \\
Neither &.. &.. &. &.. &. &.. & 1 & 3 & 0 & 2 & 0 & 3 & 0 & 0 & 9 & 0.07 \\
\hline Total.. &.. &.. &.. &.. &.. &.. & 3 & 11 & 0 & 4 & 2 & 4 & 1 & 0 & 25 & \\
\hline
\end{tabular}

Patients who had marplan before placebo

\begin{tabular}{|c|c|c|c|c|c|c|c|c|c|c|c|c|c|c|c|}
\hline $\begin{array}{l}\text { Both .. } \\
\text { Placebo only } \\
\text { Marplan only } \\
\text { Neither }\end{array}$ & $\begin{array}{l}\ldots \\
\ldots \\
\ldots \\
\ldots\end{array}$ & $\begin{array}{l}. . \\
. \\
.\end{array}$ & $\begin{array}{l}. . \\
\cdots \\
\ldots\end{array}$ & $\begin{array}{l}. . \\
\ldots \\
\ldots\end{array}$ & $\begin{array}{l}. \\
\ldots \\
\ldots\end{array}$ & $\begin{array}{l}1 \\
1 \\
1 \\
0\end{array}$ & $\begin{array}{l}1 \\
6 \\
1 \\
3\end{array}$ & $\begin{array}{l}0 \\
0 \\
0 \\
0\end{array}$ & $\begin{array}{l}1 \\
1 \\
1 \\
1\end{array}$ & $\begin{array}{l}1 \\
0 \\
1 \\
0\end{array}$ & $\begin{array}{l}2 \\
0 \\
1 \\
1\end{array}$ & $\begin{array}{l}0 \\
1 \\
0 \\
0\end{array}$ & $\begin{array}{l}0 \\
0 \\
0 \\
0\end{array}$ & $\begin{array}{l}6 \\
9 \\
5 \\
5\end{array}$ & 0.42 \\
\hline Total .. & .. & .. & .. & .. & .. & 3 & 11 & 0 & 4 & 2 & 4 & 1 & 0 & 25 & \\
\hline
\end{tabular}

All patients

\begin{tabular}{|c|c|c|c|c|c|c|c|c|c|c|c|c|c|c|c|}
\hline $\begin{array}{l}\text { Both .. } \\
\text { Placebo only } \\
\text { Marplan only } \\
\text { Neither } \quad . .\end{array}$ & $\begin{array}{l}\cdots \\
\cdots \\
\cdots \\
.\end{array}$ & $\begin{array}{l}\ldots \\
\cdots \\
\cdots \\
\cdots\end{array}$ & $\begin{array}{l}\ldots \\
\cdots \\
\cdots\end{array}$ & $\begin{array}{l}\ldots \\
\cdots \\
\cdots\end{array}$ & $\begin{array}{l}\cdots \\
\cdots \\
\cdots \\
\cdots\end{array}$ & $\begin{array}{l}1 \\
2 \\
2 \\
1\end{array}$ & $\begin{array}{l}4 \\
7 \\
4 \\
7\end{array}$ & $\begin{array}{l}0 \\
0 \\
0 \\
0\end{array}$ & $\begin{array}{l}1 \\
1 \\
3 \\
3\end{array}$ & $\begin{array}{l}2 \\
0 \\
1 \\
1\end{array}$ & $\begin{array}{l}2 \\
0 \\
4 \\
2\end{array}$ & $\begin{array}{l}1 \\
1 \\
0 \\
0\end{array}$ & $\begin{array}{l}0 \\
0 \\
0 \\
0\end{array}$ & $\begin{array}{l}11 \\
11 \\
14 \\
14\end{array}$ & 0.69 \\
\hline Total. & .. & $\ldots$ & .. & .. & .. & 6 & 22 & 0 & 8 & 4 & 8 & 2 & 0 & 50 & \\
\hline
\end{tabular}

$A=$ males, under 55 , severity +

$\mathrm{B}=$ males, 55 and over, severity + $\mathrm{C}=$ males, under 55 , severity ++

$\mathrm{D}=$ males, 55 and over, severity ++

$E=$ females, under 55 , severity +

$\mathrm{F}=$ females, 55 and over, severity +
$\mathrm{G}=$ females, under 55 , severity ++

$\mathrm{H}=$ females, 55 and over, severity ++

$\mathbf{P}=$ approximate probability of observed or greater difference in number of preferences for placebo and marplan occurring by chance.

\section{SUMMARY}

A "within patients" clinical trial of isocarboxazid ("marplan") (30 mgm. daily for three weeks) compared with a placebo (of similar dosage) was conducted under "double blind" conditions on 50 patients with moderate or severe anginal pain. The trial was designed to have a 95 per cent power of detecting as significant, at the conventional 5 per cent level, a real difference between treatments of 35 per cent or more in the proportion of patients reporting a successful treatment. Of 25 patients $\frac{7}{O}$ implying a preference, 14 favoured marplan and 11 favoured the placebo compared with $12 \cdot 5$ expected in favour of each on the null hypothesis. As $\mathrm{P}=0.69$, no significant difference between $\mathrm{N}$ marplan as administered and the placebo was detected.

It is a pleasure to record our thanks to Drs. Margaret Corbett and Sam Bayliss of Roche Products Ltd., to Drs. C. F. Brennan, and J. J. Robb of the Downe Hospital and to Miss W. Crawford, Nurse E. Caughey, Nurse A. McNeill, Miss J. Fletcher and Mrs. D. Hutton for their co-operation in various aspects of the trial.

\section{REFERENCES}

Armitage, P. (1960). Sequential Medical Trials. Blackwell, London.

Murphy, F. M. and Barber, J. M. (1960). Cardiologia, 37, Supp. 2, 117. Murphy, F. M.

,,- , and Kilpatrick, S. J. (1961). Lancet, 1, 139. 